\title{
Boxing clever
}

\author{
Peter D Toon London
}

\section{Editor's note}

At the coalface is a new series in which readers relate an ethical dilemma they have experienced themselves in the course of their work. The journal is keen to publish such reports and any reader wishing to contribute should send his or her paper (of not more than 1500 words) to the Editor, Journal of Medical Ethics, IME Publications, 151 Great Portland Street, London W1N SFB. Contributions can be published anonymously if the writer wishes.

One of the fascinations of general practice lies in its unpredictability. In the middle of the undramatic routine of acne, blood-pressure, colds and diabetes may walk a patient with malaria, a pneumothorax or an acute bleed. Similarly the ethically aware general practitioner will find a totally unforeseen ethical dilemma amongst the standard fare of conflicts about respecting the autonomy of patients who want to be paternalised, and the endless problems of confidentiality viz a viz employers, insurance companies, the worried son in Southend and the nosy neighbour. Like all general practice problems these require an immediate response. There is no time to consult the local ethics committee, or to refer to the district general hospital's consultant philosopher (even were the health authority to be enlightened enough to employ one). The patient expects some sort of answer at the end of the ten-minute consultation.

Such a problem arose one Friday morning when a teenage boy and his mother walked into my consulting room. More spots? No, he had a form in his hand. Would I fill it in to say that he was medically fit to box?

Philosophical concepts flashed before my eyes. Try linguistic analysis; what does medically fit to box mean? Having listened to the debate at the British Medical Association (BMA) on their report on boxing, I found it difficult to ascribe any meaning to those words. The human cranium is not designed to have repeated blows directed at it, and is likely to be damaged by a sport where this is the main aim. Surely

\section{Key words}

General practice: 'boxing' ethics; doctor-patient relationship. one can no more speak of being fit to box than of being $\stackrel{\oplus}{\vec{D}}$ fit to jump under a number 11 bus?

What about deontology; will that solve my problem? Clearly he has the right to box if he so wishes; true his age (fifteen) may raise issues over his autonomy to consent. His mother, his legal guardian, however is $\vec{c}$ quite happy for him to pursue his brain-damaging macho hobby - 'It's all right by me, it's what he wants ${ }^{\Phi}$ to do'. Am I just being a paternalistic, nannying $\vec{\oplus}$ fusspot, trying to interfere with his fun?

On the other hand he has no right, natural or contractual, to ask this service of me. So far as I am aware boxing medicals do not form part of those services 'usually offered by general medical practitioners' which my Family Practitioner would deem it negligent of me to withhold. Is there $a \stackrel{\overrightarrow{7}}{\Rightarrow}$ conscience clause with respect to boxing?

Try utilitarianism. What are the likely consequences of my possible actions? If I refuse to fill in the form, then surely he will just get someone else to do it? If I fill it in, then I am unlikely to be deluged with a flood of $\bar{\Phi}$ teenage would-be Henry Coopers; I do not imagine this:wedge has a particularly thick end. So does it really 3 . matter? On the other hand, one consequence of whatever decision I make will be its effect on me; how will I feel if I complete, or do not complete, the form?

My nine-minute explanation of the dangers of boxing failed to impress him, or his mother; the timeo had come when a decision had to be made, so that the ears of the next in line could be uncontroversiallyo syringed. In the end I decided that doctors have rights $N$ too, and why should I spend the weekend worrying N about his cauliflower ears and sub-dural haemorrhage? So like Pontius Pilate I washed my hands (a wellknown medical ploy to gain time) and in the eleventh minute told him that $I$ had no intention of signing hise form, and that if he insisted on damaging his, or someone else's brain, then he must find anothero medical accomplice.

Dr Peter D Toon MBBS (Lond) MSc (Oxon) MRCGP DPMSA is NHS GP Principal at 206 Queensbridge Rd, London E8 $3 N B$ and Senior Tutor in the Department of General Practice and Primary Care at St Bartholomew'so․ and the London Hospitals. 